Bull. Mater. Sci., Vol. 35, No. 2, April 2012, pp. 253-258. (c) Indian Academy of Sciences.

\title{
High resolution X-ray diffraction studies on unirradiated and irradiated strontium hexaferrite crystals
}

\author{
BALWINDER KAUR, MONITA BHAT, F LICCI ${ }^{\dagger}$, RAVI KUMAR ${ }^{\dagger \dagger}$, K K BAMZAI \\ and P N KOTRU* \\ Department of Physics and Electronics, University of Jammu, Jammu 180 006, India \\ $\dagger$ Instituto MASPEC - CNR, Via Chiavari 18/A, 43100 Parma, Italy \\ ${ }^{\dagger}$ Nuclear Science Centre, New Delhi 110 067, India
}

MS received 19 March 2011

\begin{abstract}
High-resolution X-ray diffraction technique, employing a three-crystal monochromator-collimator combination is used to study the irradiation induced defects in flux grown Sr-hexaferrite crystals irradiated with $50 \mathrm{MeV} \mathrm{Li}^{3+}$ ion beams at room temperature with a fluence value of $1 \times 10^{14} \mathrm{ions} / \mathrm{cm}^{2}$. The diffraction curves of the irradiated crystals suggest the possibility of creation of low angle grain boundaries and other point/clusters of defects causing amorphization in the irradiated crystals. The perfection of the irradiated and unirradiated (0001) cleaved surfaces of the crystals is studied using the bulk method of X-ray topography. The topographs supplement the findings suggestive of modifications in the crystalline quality of $\mathrm{SrFe}_{12} \mathrm{O}_{19}$ on irradiation with $\mathrm{SHI}$ of $\mathrm{Li}^{3+}$. Etching of the (0001) cleaved surfaces in $\mathrm{H}_{3} \mathrm{PO}_{4}$ at $120^{\circ} \mathrm{C}$ suggests that the dissolution characteristics of the surfaces get affected on irradiation with $\mathrm{SHI}$ of $\mathrm{Li}^{3+}$, besides supporting the findings of HRXRD and X-ray topography regarding modifications in the perfection of $\mathrm{SrFe}_{12} \mathrm{O}_{19}$ on irradiation.
\end{abstract}

Keywords. Ion irradiation; amorphization; defects; Sr-hexaferrite crystal; X-ray diffraction; topography.

\section{Introduction}

The crystal structure of $\mathrm{SrFe}_{12} \mathrm{O}_{19}$ was first determined by Adelskold (1938) which is isomorphous with magnetoplumbite. Other workers (Bertaut et al 1959; Obraders et al 1988; Kimura et al 1990) further confirmed his determination by structural refinements of $\mathrm{SrFe}_{12} \mathrm{O}_{19} \cdot \mathrm{SrFe}_{12} \mathrm{O}_{19}$ has hexagonal symmetry with space group $P 63 / \mathrm{mmc}$. The lattice parameters for $\mathrm{SrFe}_{12} \mathrm{O}_{19}$ are $a=5.883 \AA$ and $c=$ 23.046 $\AA$ (Licci et al 1983). There are two formula units in a unit cell. Hexaferrites with the magnetoplumbite or related structures seem most promising because of their strong magnetic anisotropy (Eschenfeldar 1980; Nicolas 1980). Hexagonal hard ferrites, the prototype of which is represented by $\mathrm{SrFe}_{12} \mathrm{O}_{19}$ and $\mathrm{BaFe}_{12} \mathrm{O}_{19}$, are also considered to be the most promising particulate media for perpendicular recording due to their chemical, morphological and magnetic characteristics such as $\mathrm{mm}$ - devices, master tapes, magnetic heads and several others (Speliotis 1987).

The modification caused by energetic ions in solids depends upon ion energy, fluence, temperature and ion species. Irradiation with swift heavy ions cause damages in the materials, consequently leading to modifications in their characteristics (Toulemonde 1991; Szenes 1995). Defects generate stress/strain in the materials, which modify their

\footnotetext{
*Author for correspondence (pnkotru@ rediffmail.com)
}

physical properties (Studer and Toulemonde 1992; Kumar et al 1998). Swift heavy ion (SHI) irradiation has become an interesting field for the last two decades especially for magnetic oxides and ferrites (Studer et al 1988; Meftah et al 1991; Studer and Toulemonde 1992; Pascard and Studer 1997). It is already reported that swift heavy ions in $\mathrm{MeV}$ range can produce additional defects, create phase transformation and give rise to anisotropic growth in some materials. Because of irradiation, damage is produced in the near surface region of the substrate leading to stress and amorphization in structures causing cracking, delamination, anomalous diffusion of dopants and void formation (Volkert 1991; Singh et al 2000).

The irradiation effects induced by highly energetic ions (Ar, $\mathrm{Kr}$ and $\mathrm{Xe},>1 \mathrm{GeV}$ ) in ferrimagnetic oxides, $\mathrm{Y}_{3} \mathrm{Fe}_{5} \mathrm{O}_{12}$ and hexaferrite, $\mathrm{BaFe}_{12} \mathrm{O}_{19}$, using vibrating sample magnetometry and Mössbauer spectroscopy, have been reported (Studer et al 1987). Latent tracks are reported to have been observed by high-resolution electron microscopy in both types of oxides (Toulemonde et al 1987). Magnetic investigations are reported in the literature to describe latent track formation as induced by high electronic energy loss (using $3.1 \mathrm{GeV}$ xenon and $2.3 \mathrm{GeV}$ molybdenum ions as radiation) in hexaferrites of the type, $\mathrm{AFe}_{12} \mathrm{O}_{19}(\mathrm{~A}=\mathrm{Ba}$ and Sr) (Houpert et al 1988). These workers have considered damage processes and magnetic field orientation in these oxides on irradiation by high energy ions (Studer et al 1987; Toulemonde et al 1987; Houpert et al 1988). Consequences 
of $85 \mathrm{MeV}{ }^{16} \mathrm{O}$ ion irradiation on magnetization behaviour of micron-sized and nano-sized powders of hexagonal ferrites $\left(\mathrm{SrFe}_{12} \mathrm{O}_{19}\right)$ are also reported (Shinde et al 1998). These powders were characterized by using vibrating sample magnetometry (VSM), Mössbauer spectroscopy and scanning electron microscopy (SEM). It was reported that irradiation modifies the magnetic properties of micron-sized powders, but not of nano-sized powders. The irradiation effects with heavy ions like $\mathrm{Xe}$, Mo in $\mathrm{GeV}$ energy range and oxygen ion in $\mathrm{MeV}$ range on Sr-hexaferrite are already reported in the literature (Houpert et al 1988). However, there is no report on the studies of $\mathrm{Li}^{3+}$ ion irradiation effects with energy, $50 \mathrm{MeV}$, concerning structural aspects of $\mathrm{SrF}_{12} \mathrm{O}_{19}$. So the main objective of this investigation is to examine the effects on the structure of Sr-hexaferrite with $\mathrm{Li}^{3+}$ ion having an energy of $50 \mathrm{MeV}$.

It is reported in the literature (Goshchitskii et al 1987) that physical properties of oxide compounds get more affected by such physical processes i.e. irradiation as it may redistribute various cations over non-equivalent sites of a crystal lattice. Such a non-uniform shifting of ions is observed in garnet structure (Chukalkin and Shtirts 1994), which leads to amorphization.

$\mathrm{X}$-ray diffraction techniques are widely used as nondestructive direct methods for analysing defects and dislocations in nearly perfect crystals (Lang 1958, 1970; Kato 1992; Bowen and Tanner 1998). Crystallography has become an integral part of all disciplines as it is concerned with the determination of structure of crystals. The materials with their well-understood characteristics form the main part of the modern technology advances and industrial production (Lal 1993). So, it is necessary to have a correlation between their properties and the basic materials characteristics (NAS and NAE Report 1967; Laudise 1975; Lal 1988). Among all the techniques viz. etching, TEM, birefringence, X-ray topography and high resolution X-ray diffraction, the last one i.e. high resolution X-ray diffraction, has remarkable features (Lal 1993). High resolution X-ray diffraction topography and diffractometry have been found to be useful for the direct observation of lattice defects in single crystals and provide valuable feedback for improving structural perfection of crystals. A five-crystal X-ray diffractometer was set in $(+,-,+)$ geometry. With this arrangement, the characteristic $\mathrm{K}_{\alpha}$ doublet is resolved into $\mathrm{K}_{\alpha 1}$ and $\mathrm{K}_{\alpha 2}$ components. Highly monochromated and well collimated $\mathrm{K}_{\alpha 1}$ beam is isolated with the help of a fine slit and is used as the exploring beam. In the present investigation, Mo $\mathrm{K}_{\alpha 1}$ radiation has been used. With this arrangement, a highly resolved X-ray beam is obtained by which diffraction curves of nearly perfect crystals are even sharper with half widths of only a few seconds of arc, resulting into a much greater resolution.

In the present investigation, we have irradiated crystals with $50 \mathrm{MeV} \mathrm{Li}^{3+}$ ion beam. The irradiation has influenced the mechanical (Kaur et al 2004), dielectric (Kaur et al 2007) and magnetic (Kaur et al 2006) characteristics of Srhexaferrite crystals and we have already reported the same. However, it is important to know as to what extent does irradiation influence the crystallinity of the materials which eventually leads to modifications in the overall characteristics of materials. In order to see the damage created by irradiation, we have used high-resolution X-ray diffraction technique. X-ray topography and etching technique have also been used as supplementary probes. In the present case, we have conducted studies only on the crystals irradiated with a $50 \mathrm{MeV} \mathrm{Li}^{3+}$ with a fluence value of $1 \times 10^{14} \mathrm{ions} / \mathrm{cm}^{2}$.

\section{Experimental}

Crystals of $\mathrm{SrFe}_{12} \mathrm{O}_{19}$ were grown by high temperature solution technique i.e. flux method. The supersaturated high temperature solution (with soaking temperature, $1350^{\circ} \mathrm{C}$ for $24 \mathrm{~h}$ ) was slowly cooled $\left(5-7 \cdot 8^{\circ} \mathrm{C} / \mathrm{h}\right)$ in platinum crucible having $70 \%$ molar concentration of ferrite composition $\left(\mathrm{SrCO}_{3}, \mathrm{Fe}_{2} \mathrm{O}_{3}\right)$ and $30 \%$ flux $\left(\mathrm{Na}_{2} \mathrm{CO}_{3}\right)$ (Rinaldi and Licci 1984).

Crystals of $\mathrm{SrFe}_{12} \mathrm{O}_{19}$ were irradiated with $50 \mathrm{MeV} \mathrm{Li}^{3+}$ ion beams at room temperature with a fluence value of $1 \times$ $10^{14}$ ions $/ \mathrm{cm}^{2}$. This irradiation experiment was performed by using 15 UD Pelletron Accelerator at the Nuclear Science Centre, New Delhi. The range of the $50 \mathrm{MeV} \mathrm{Li}^{3+}$ ion beams was calculated using TRIM/SRIM calculations (Zeigler and Manoyan 1988). From TRIM calculations, it was ensured that the thickness of the crystals was comparable with the range of the ions.

High resolution X-ray diffraction (HRXRD) technique employing a three-crystal monochromator-collimator combination was used to study the irradiation-induced defects in single crystals (Lal 2002). The diffraction curves of the single crystals were recorded with (008) diffraction planes and Mo $\mathrm{K} \alpha_{1}$ radiation by using $(+,-,+)$ geometry of the five-crystal X-ray diffractometer (Lal 1993, 1998). X-ray topographs were recorded using X-ray diffraction topography camera developed at the National Physical Laboratory, New Delhi (Verma and Srivastav 1991). Etching experiments were conducted by using $\mathrm{H}_{3} \mathrm{PO}_{4}$ (conc. $85 \%$ ) at $120^{\circ} \mathrm{C}$ for $20 \mathrm{~min}$ as an etchant for (0001) cleavages of $\mathrm{SrFe}_{12} \mathrm{O}_{19}$.

\section{Results and discussion}

Figure 1 shows high resolution $\mathrm{X}$-ray diffraction curve of a flux grown $\mathrm{SrFe}_{12} \mathrm{O}_{19}$ crystal with (008) diffraction planes, using five-crystal X-ray diffractometer in the geometry $(+,-,+)$ of three crystals. It is clear from this figure that there is a very sharp peak having half width $\approx 5.6$ arc s. A very smooth peak with highly diffracted X-ray intensity is recorded. It is already quoted in the literature (Lal and Goswami 1988; Zeigler and Manoyan 1988; Lal 1998, 2002) that diffraction curves of good quality crystals have half widths of 5-10 arc $\mathrm{s}$ which suggests that $\mathrm{SrFe}_{12} \mathrm{O}_{19}$ crystal used in this investigation is nearly perfect.

In order to study the effect of SHI irradiation on the crystalline quality of $\mathrm{SrFe}_{12} \mathrm{O}_{19}$, the crystal was exposed to $50 \mathrm{MeV} \mathrm{Li}^{3+}$ ion beam at a fluence of $1 \times 10^{14}$ ions $/ \mathrm{cm}^{2}$. 
Figure 2 shows the diffraction curve of $\mathrm{SrFe}_{12} \mathrm{O}_{19}$ irradiated with this radiation. From the figure, it is very clear that there is a sharp decline in the X-ray diffracted intensity. Also smoothening of curve disappears and instead a diffused peak appears in the irradiated crystal. The variation in the shape of the diffraction curve at different regions suggests a variation in the degree of perfection (Lal et al 2003). The appearance of small peaks in the diffraction curve as shown in figure 2 also suggests a possibility of the creation of low angle grain boundaries in the irradiated crystal of $\mathrm{SrFe}_{12} \mathrm{O}_{19}$. Half width increases from 5.6 arc s (figure 1) in case of pristine to 31 arc s (figure 2) in case of irradiated crystal. The irradiation has not only brought

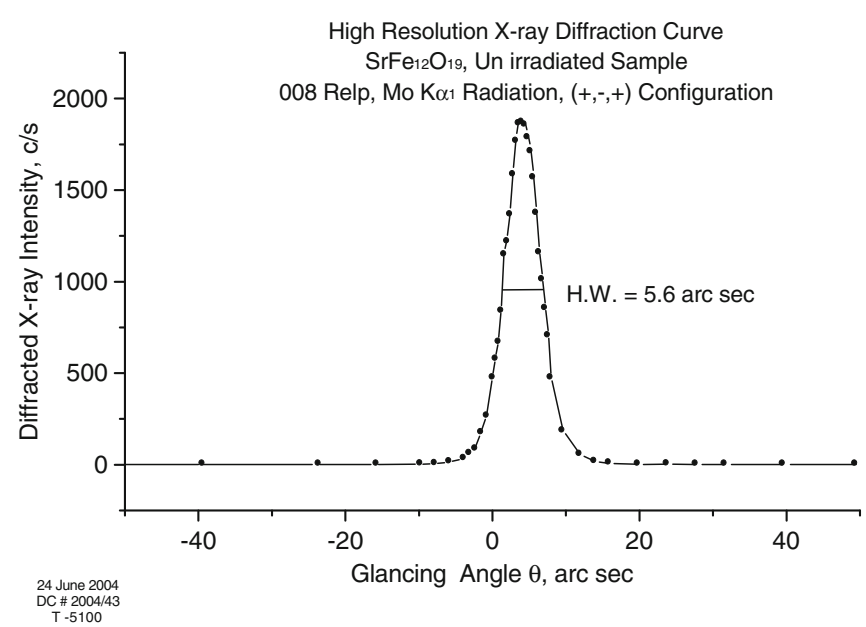

Figure 1. Typical diffraction curve of pristine $\mathrm{SrFe}_{12} \mathrm{O}_{19}$ single crystal recorded with help of high resolution X-ray diffractometer on (008) diffracting planes.

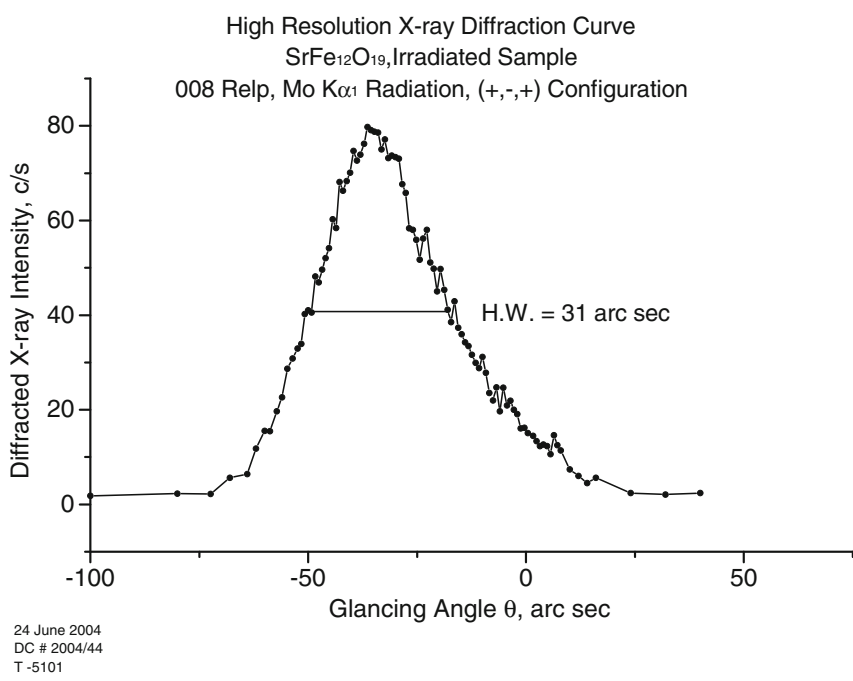

Figure 2. High resolution X-ray diffraction curve of irradiated $\mathrm{SrFe}_{12} \mathrm{O}_{19}$ single crystal recorded with help of five-crystal X-ray diffractometer in $(+,-,+)$ configuration. down the peak value of diffracted X-ray intensity considerably but also greatly widened its half width suggesting creation of point/clusters of defects besides amorphization in the irradiated crystals as has also been reported for Insubstituted Mg-Mn ferrites (Singh et al 2002; Dogra et al 2004). The disappearance of smoothness in the diffraction curves of irradiated crystal (figure 2) implies that stress/strain is generated in the crystals.

A direct comparison between two diffraction curves before and after irradiation of $\mathrm{SrFe}_{12} \mathrm{O}_{19}$ crystals is reflected in figure 3. It is clear that the irradiation with lithium ion beam causes critical changes in the crystallinity of Sr-hexaferrite. The sharp and smooth diffraction peak, which is characteristic of crystallinity and perfection of pristine $\mathrm{SrFe}_{12} \mathrm{O}_{19}$, becomes almost flat with very diffused maxima on irradiation with $50 \mathrm{MeV} \mathrm{Li}^{3+}$ ions. Creation of amorphization state in the irradiated Sr-hexaferrite has also been reported in the case of $\mathrm{YFeO}_{3}$ (Chukalkin and Goshchitskii 2003), wherein it is also reported that even exposure to such high-energy heavy ions leads to atom-atom displacement cascade many times.

It is interesting to probe perfection through the bulk of unirradiated and irradiated (0001) cleaved portions of the same crystal, using X-ray topography. Figure 4(a) is a high resolution X-ray diffraction topograph, taken in reflection geometry and $(+,-,+)$ configuration, on using Mo $\mathrm{K} \alpha_{1}$ radiation, of an unirradiated $\mathrm{SrFe}_{12} \mathrm{O}_{19}$ crystal. Figure 4(b) is the X-ray topograph of an irradiated cleaved portion of the $\mathrm{SrFe}_{12} \mathrm{O}_{19}$ crystal taken under identical conditions as that of figure 4(a). The exposure time was maintained the same for both unirradiated as well as irradiated samples. Both are stationary topographs and recorded from the middle of the specimens. In the plane of the diffraction, their widths were $0.6 \mathrm{~mm}$ for these crystals. In the plane perpendicular to the diffraction plane, the exploring beam bathed entire length of the specimen. One does observe discontinuity in

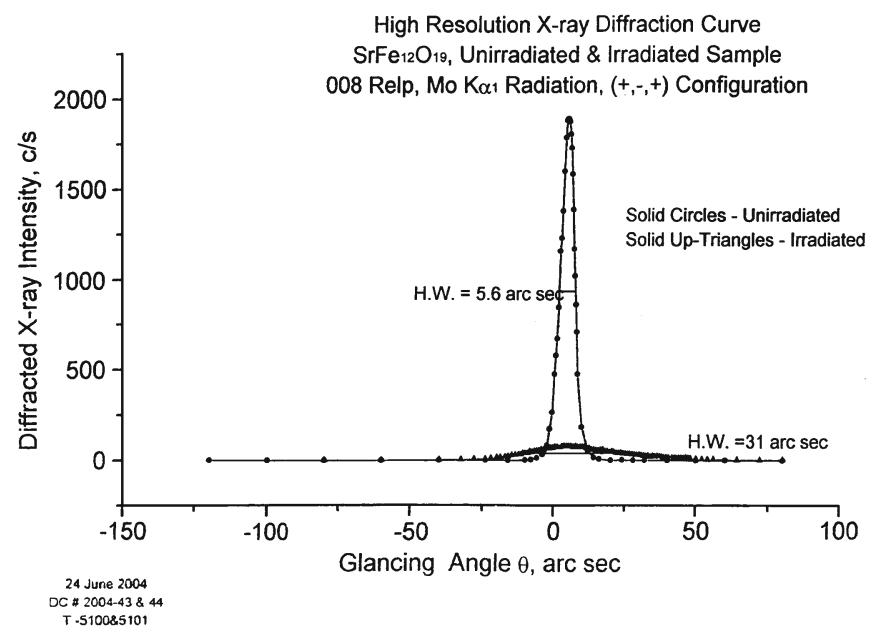

Figure 3. A plot showing comparison between X-ray diffraction curves of unirradiated (UIR) and irradiated (IR) $\mathrm{SrFe}_{12} \mathrm{O}_{19}$ crystals. 
the diffracted intensity from the unirradiated $\mathrm{SrFe}_{12} \mathrm{O}_{19}$ sample (figure 4(a)) which does show most of it as nearly perfect, ignoring the presence of some grain/subgrains. Similar studies on scanning of a large number of other virgin samples of $\mathrm{SrFe}_{12} \mathrm{O}_{19}$ demonstrated most of the areas as being nearly perfect. It is, however, clear that individual grain of the unirradiated crystal as is revealed by figure 4(a) is of high crystalline quality. The same is supported by the peak intensity and half width of their diffracted X-ray beam of unirradiated sample of figure 1 . There is a considerable decrease in the intensity of the X-ray topographs of irradiated $\mathrm{SrFe}_{12} \mathrm{O}_{19}$ which suggests decrease in crystalline quality of the specimen upon irradiation (see figure 4(b)). The non-uniformity in the intensity of X-rays throughout the irradiated sample could also be due to generation of defects in the crystal. The dotted area depicts portion of the irradiated crystal which suggests a highly defective region or a misoriented portion.
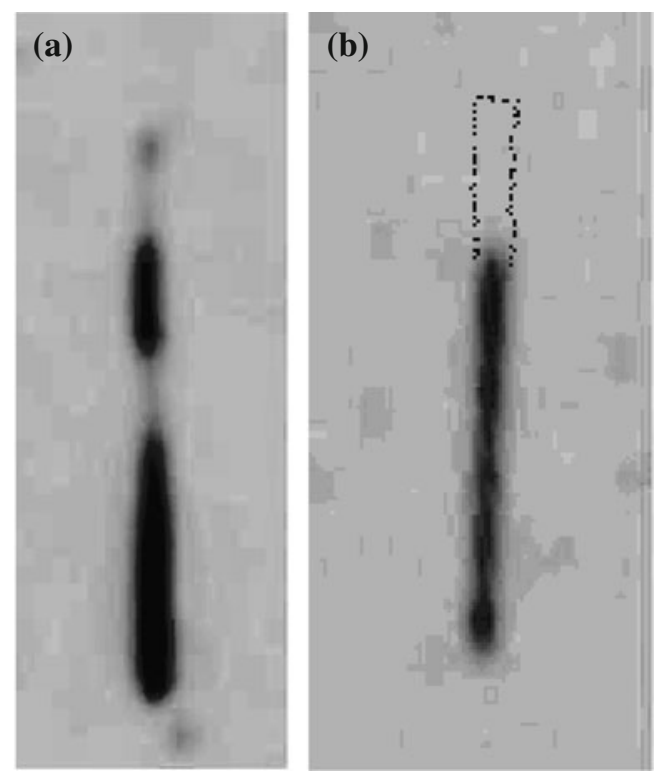

Figure 4. High resolution $\mathrm{X}$-ray diffraction topographs of (a) unirradiated and (b) irradiated $\mathrm{SrFe}_{12} \mathrm{O}_{19}$ crystals.
Decrease in the diffracted intensity and broadening of the diffraction curve half-width on irradiation was observed to be common to all the specimens studied during the present investigation. Thus, the X-ray diffraction topographs supplemented by high-resolution XRD curves, clearly suggest the modifications in the crystalline quality of $\mathrm{SrFe}_{12} \mathrm{O}_{19}$ on irradiation with SHI of $\mathrm{Li}^{3+}$.

$\mathrm{The} \mathrm{Li}^{3+}$ ion irradiation effects on mechanical, dielectric and magnetic properties have already been reported (Kaur et al 2004, 2006, 2007). The main cause behind these modifications in the characteristics is shown to be mostly resulting from imperfections generated by the passage of $\mathrm{Li}^{3+}$ ions through hexaferrite crystals leading to amorphization and generation of other defects as is clearly demonstrated by the high resolution X-ray diffraction results discussed above in Sr-hexaferrite.

Delineation of structural defects in crystals by chemical etch method is very well known. The same has been used for the revelation of defects in pure and $\mathrm{Ga} / \mathrm{In}$ substituted strontium hexaferrites (Raina et al 1996). It was felt interesting to see what etching technique reveals about irradiation effects on strontium hexaferrite. Figure 5(a) is a photomicrograph of (0001) unirradiated cleavage surface of $\mathrm{SrFe}_{12} \mathrm{O}_{19}$ etched in $85 \% \mathrm{H}_{3} \mathrm{PO}_{4}$ at $120^{\circ} \mathrm{C}$ for $20 \mathrm{~min}$. Deep hexagonal pits at isolated sites suggestive of their formation at dislocation sites are seen. Besides this, very few shallow pits developed at some superficial defects are also noticed. Etching of a large number of cleavages suggests a low defect density. For irradiated sample, however, the density of etch pits was so high as to make it difficult to measure the density. Etching behaviour of $\mathrm{Li}^{3+}$ ion irradiated (0001) cleavages of $\mathrm{SrFe}_{12} \mathrm{O}_{19}$ (figure 5 (b)) was observed to be different under similar conditions of etching. Either bunch of etch channels were formed or high density of very shallow pits were observed. Irradiation with $\mathrm{Li}^{3+}$ ions produce trail of defects as they pass through the cleaved surface which includes amorphization and several other defects. The dissolution characteristics leading to rate of etching perpendicular and parallel to the (0001) surfaces get severely affected, leading to heavily eroded regions of shallow pits. The density of shallow etch pits increase many
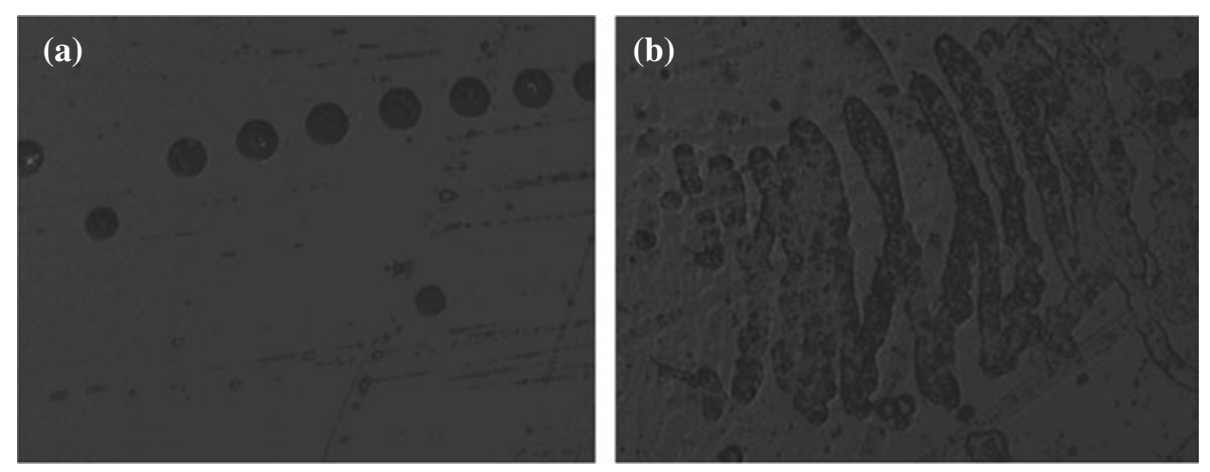

Figure 5. Photomicrographs showing (0001) cleavage surface etched in $\mathrm{H}_{3} \mathrm{PO}_{4}$ of (a) unirradiated and (b) irradiated $\mathrm{SrFe}_{12} \mathrm{O}_{19}$ crystal. 
fold on irradiation with $\mathrm{Li}^{3+}$ ions. The results of etching (a surface method) fully support the findings of high resolution $\mathrm{X}$-ray diffraction and the bulk method like X-ray topography.

\section{Conclusions}

From the high resolution X-ray diffraction, X-ray topography and etching studies on pristine and $50 \mathrm{MeV} \mathrm{Li}^{3+}$ ion beam irradiated crystals of $\mathrm{SrFe}_{12} \mathrm{O}_{19}$, one may conclude the following:

The shape and smooth diffraction peak characteristics of perfection and single crystallinity of pristine crystals gets flattened in case of irradiated crystals. The half width increases from 5.6 arc s (corresponding to good quality pristine crystals) to 31 arc s after irradiation. All this is attributed to the presence of point/clusters of defects in the Sr-hexaferrite crystals created as a result of irradiation. The flattening of the peak in irradiated crystal suggests the presence of amorphization state in the $\mathrm{SrFe}_{12} \mathrm{O}_{19}$ after irradiating with $50 \mathrm{MeV} \mathrm{Li}^{3+}$ ion beam. The X-ray topography supplements the findings that irradiation leads to substantial decrease in the crystalline quality of $\mathrm{SrFe}_{12} \mathrm{O}_{19}$ crystals which ultimately becomes the cause of modifications in the overall characteristics of the crystal. The etching studies confirm that the dissolution rate parallel $\left(v_{\mathrm{s}}\right)$ and perpendicu$\operatorname{lar}\left(v_{\mathrm{n}}\right)$ to the surface change drastically on irradiation with $\mathrm{Li}^{3+}$ ions. While $\mathrm{H}_{3} \mathrm{PO}_{4}$ at $120^{\circ} \mathrm{C}$ for 20 min leads to formation of hexagonal point bottomed pits at the dislocation sites for pristine cleaved (0001) surfaces, the etching under identical conditions leads to the formation of heavily eroded shallow pits in most of the regions of irradiated (0001) cleavage surfaces. The density of pits rises many fold on irradiation.

\section{Acknowledgements}

The authors are thankful to the Nuclear Science Centre (NSC), New Delhi, for providing funds under UFUP Scheme No. 30312. One of the authors (BK) is thankful to the NSC for awarding a project fellowship. Part of this work has received funding from DST, New Delhi, for the project under SERC (Science) Scheme. The work reported in this paper forms a part of the Ph.D programme of one of the authors (BK) under the supervision of Dr K K Bamzai. The corresponding author is thankful to the UGC, New Delhi, for the award of a Emeritus fellowship, enabling him to carry forward the present work. The authors are thankful to Dr Krishan Lal, NPL, New Delhi, for providing the high resolution X-ray diffraction and X-ray topography facilities.

\section{References}

Adelskold V 1938 Arkiv Kemi Miner. Geol. A12 1

Bertaut E F, Deschamps A, Pauthenet R and Pickart S 1959 J. Phys. Radiat. 20404
Bowen D K and Tanner B K 1998 High resolution X-ray diffractometry and topography (London: Taylor and Francis Ltd)

Chukalkin Yu G and Shtirts V R 1994 Phys. Status Solidi (a) 1449

Chukalkin Yu G and Goshchitskii B N 2003 Phys. Status Solidi (a) 200 R9

Dogra A, Kumar R, Khan S A, Siva Kumar V V, Kumar N and Singh M 2004 Nucl. Instrum. Meth. B225 283

Eschenfeldar A H 1980 Magnetic bubble technology (Berlin: Springer Verlag)

Goshchitskii B N, Arkhipov V E and Chukalkin Yu G 1987 Sov. Sci. Rev. A, Phys. Rev. 8519

Houpert Ch, Nguyen N, Studer F, Groult D and Toulemonde M 1988 Nucl. Instrum. Meth. B34 228

Kato N 1992 J. Acta Crystallogr. A48 834

Kaur B, Bhat M, Licci F, Kumar R, Kotru P N and Bamzai K K 2004 Nucl. Instrum. Meth. B222 175

Kaur B, Bhat M, Licci F, Kumar R, Kulkarni S D, Joy P A, Bamzai K K and Kotru P N 2006 J. Magn. Magn. Mater. 305392

Kaur B, Bhat M, Licci F, Kumar R, Bamzai K K and Kotru P N 2007 Mater. Chem. Phys. 103255

Kimura K, Ohgaki M, Tanaka K, Morikawa H and Marumo F 1990 J. Solid State Chem. 87186

Kumar R, Samanta S B, Arora S K, Gupta A, Kanjilal D, Pintoo R and Narlikar A V 1998 Solid State Commun. 12805

Lal K 1988 in 40 Years of research-A CSIR overview series II (New Delhi: CSIR) p. 1

Lal K 1993 Bull. Mater. Sci. 16617

Lal K 1998 Proc. Indian Nat. Sci. Acad. A64 609

Lal K 2002 Proc. Indian Nat. Sci. Acad. A68 315

Lal K and Goswami S N N 1988 Rev. Sci. Instrum. 591409

Lal K, Anantha Murthy R V, Choubey A and Goswami N 2003 in Crystal growth technology (eds) K Byrappa and T Ohachi (Springer - William Andrew Publishing) pp. 387-413

Lang A R 1958 J. Appl. Phys. 29597

Lang A R 1970 in Modern diffraction and imaging techniques in material science (eds) S Amelinckx et al (Amsterdam: North Holland) p. 407

Laudise R A 1975 in Crystal growth and characterization (eds) R Ueda et al (Amsterdam: North Holland) p. 255

Licci F, Rinaldi S and Besagni T 1983 Mater. Lett. 1163

Meftah A, Merrien N, Nguyen N, Studer F, Pascard H and Toulemonde M 1991 Nucl. Instrum. Meth. B59-60 605

National Acad. Sci. and National Acad. Engg. Comm. Materials Advisory Board - MAB Report 229 - M 1967, Washington DC

Nicolas J 1980 in Ferromagnetic materials (ed) E P Wohlfarth (Amsterdam: North Holland)

Obraders X, Solans X, Collomb A, Samaras D, Rodriguez J, Pernet M and Font-Altaba M 1988 J. Solid State Chem. 72218

Pascard H and Studer F 1997 J. Phys. IV C1-211

Raina Urvashi, Bhat Sushma, Licci F and Kotru P N 1996 J. Mater. Sci. 313035

Rinaldi S and Licci F 1984 IEEE Trans. Magn. MAG - 201267

Shinde R, Bhagwat A, Patil S I, Ogale S B, Mehta G K, Date S K and Marest G 1998 J. Magn. Magn. Mater. 186342

Singh J P, Singh R, Kanjilal D, Mishra N C and Ganesan V $2000 \mathrm{~J}$. Appl. Phys. 872742

Singh M, Dogra A and Kumar R 2002 Nucl. Instrum. Meth. B196 315

Speliotis D 1987 IEEE Trans. Magn. MAG - 2325

Studer F and Toulemonde M 1992 Nucl. Instrum. Meth. B65 560 
Studer F, Groult D, Nguyen N and Toulemonde M 1987 Nucl. Instrum. Meth. B19/20 856

Studer F, Pascard H, Groult D, Houpert Ch, Nguyen N and Toulemonde M 1988 Nucl. Instrum. Meth. B32 399

Szenes G 1995 Phys. Rev. B51 8026

Toulemonde M 1991 Nucl. Instrum. Meth. B156 1
Toulemonde M, Fuchs G, Nguyen N, Studer F and Groult D 1987 Phys. Rev. B35 6560

Verma A R and Srivastav O N 1991 Crystallography applied to solid state physics (New Delhi: Wiley Eastern Limited) 2nd ed.

Volkert C A 1991 J. Appl. Phys. 703521

Zeigler J F and Manoyan J 1988 Nucl. Instrum. Meth. B35 215 